\title{
Risk of Breast Cancer in Relation to Reproductive Factors in North-west of Iran, 2013-2014
}

\author{
Afsaneh Veisy ${ }^{1 *}$, Shirin Lotfinejad ${ }^{2}$, Kamal Salehi $^{1}$, Faegh Zhian ${ }^{3}$
}

\begin{abstract}
More than one million new patients suffer from breast cancer annually in the world. In developed countries, breast cancer is the most common malignancy diagnosed among women, and in developing regions, it often ranks second to cervical cancer. This study aimed to investigate the relationship between incidence of breast cancer and reproductive factors in North-West of Iran. This retrospective analytical control-case study was conducted with 235 breast cancer patients and 235 women in the control group. Data collection tools included a set of questions with interviews and patient medical records. Data were analyzed using statistical tests: t-test, Chi-square, Fisher, and Pearson correlation coefficient. Significantly increased risks were associated between breast cancer and older age at first pregnancy, age at menopause and history of contraceptive use. A trend for decreasing risk were observed with increasing parity. Findings of this study showed no association between breast cancer and age at menarche. The study results suggested that physiological and reproductive factors may play important roles in the development breast cancer among Iranian women.
\end{abstract}

Keywords: Breast cancer - reproductive factors - oral contraceptive pills - Iran

Asian Pac J Cancer Prev, 16 (2), 451-455

\section{Introduction}

Breast cancer is the most common cancer among women in developed and developing countries (Ahmadian et al., 2012). In 2008, approximately 1.38 million new cases were diagnosed and approximately 458,000deaths were recorded both in developed and developing countries (Iskandarsyah et al., 2014). The rates of breast cancer have increased over the past two decades (Asnarulkhadi et al., 2012). The WHO estimates that by the year 2020 , the number of cases of cancer will double in developing countries (Seth et al., 2012). In Iran also, statistics indicate a huge increase in incidence of this disease Among Iranian women and It includes 22.9 percentage of invasive cancers in women and 16 percent of all cancers (Sabokbar et al., 2012). In developed countries, breast cancer is the most common malignancy diagnosed among women, and in developing regions, it ranks second to cervical cancer (Zeleniuchan et al., 2005). Among American women, breast cancer represents $32 \%$ of all new patients of cancer and is the second leading cause of cancer deaths (15\%) after lung cancer (Hadjiiski et al., 2006). It is estimated that 211,240 patients suffer from invasive breast cancer in a year in the United States. These numbers represent a sharp increase over the past 30 years (Mousavi et al., 2006).Currently, in India, the incidence of breast cancer has steadily increased over the years and as many as 100,000 new patients are being detected every year. The increase reported by the cancer registries is nearly $12 \%$ from 1985 to 2001, representing a 57\% rise in India's cancer burden (Zeleniuch, 2005; Yip et al., 2006). Number of breast cancer cases is estimated to have reached 1.2 million worldwide. The incidence could go up by $50 \%$ i.e. 1.5 million by 2020 said world cancer report 2008 . The report also points that breast cancer accounts for $16 \%$ of cancer deaths globally (Collaborative Group on Hormonal Factors in Breast Cancer, 2012). Statistics reveal a significant increase in this disease in the past 50 years, especially since 1970 . This increase has even been seen in countries like India, Japan, and Korea, which used to have the lowest rates of breast cancer (Beiki et al., 2012). What causes breast cancer? And why a double and even triple increase is seen in recent decades? The Cancer Research Center consider reproductive factors such as age at menarche, age at menopause, parity, age at first delivery, and breast feeding influential (Collaborative Group on Hormonal Factors in Breast Cancer, 1996). A study in Iran noted its risk factors as low number of childbirths, short breastfeeding period, family history, and use of contraceptives (Ghiasvand et al., 2011). A number of studies reported risk factors to include family history, early menarche, late menopause, and obesity at menopause (Collaborative Group on Hormonal Factors in Breast Cancer, 2009). Striking differences exist between countries in the incidence of breast cancer. The causes of these differences are unknown, but because incidence rates 
change in migrants, they are thought to be due to lifestyle rather than genetic differences (Tam et al., 2010). Use of oral contraceptive pills, as a potential risk factor, has long attracted interest of researchers. Contraceptive pills were globally marketed in 1960, and were made available in Iran in 1973. Some researchers are concerned that this disease increases with onset of contraceptive pill use, so that in the U.S., as in most places in the world, the increase in breast cancer has coincided with onset contraceptive pill use. The relationship between contraceptive pills and breast cancer incidence is controversial. A group of researchers concluded that use of contraceptive pills is related to and increases the incidence of breast cancer, and many reject such a relationship. The present study was conducted with the aim to determine the relationship between breast cancer and reproductive factors. The goal of this case control study was to examine breast cancer risk factors in populations with different risks for breast cancer. Since breast cancer is diagnosed in late stages in developing countries, these studies will help early prevention and timely diagnosis and treatment in highrisk people.

\section{Materials and Methods}

This is an analytical case-control study, in which the effects of risk factors on incidence of breast cancer were investigated. There were 235 subjects in each of the case and control groups.

\section{Case group}

Subjects in this group were selected by convenience sampling that attended chemotherapy and radiotherapy wards in Omid and Imam Khomaini hospitals in Urmia on daily basis. Objectives of the study were explained to the subjects, and they were interviewed after obtaining their permission. Each interview lasted 20 minutes.

\section{Control group}

Members for this group were selected through public call and from among samples attending women's clinics on daily basis. Breast examination was performed by a skillful physician. The subjects entered the study if healthy, and excluded if suspected, but were referred to relevant specialists for further examinations.

Necessary data were collected from both groups in relation to marital status, age, education, socio-economic status, history of breastfeeding, family history of cancer, history of benign mass, parity, age at menarche, regularity of menstrual cycle, use of contraceptive methods, history of diseases, history of alcohol use, history of hormone replacement therapy, history of infertility, duration of breastfeeding, use of cigarettes, history of chest radiography, and any contraindication for the pill, and then were matched with a higher number subjects in the control group. In this study, control and case groups were matched according to variables of age, socio-economic status, weight, and parity. Single women and those with history of chest radiography, family history of breast cancer, weighing over $80 \mathrm{~kg}$, lack of breast feeding, history of female infertility hormone treatment, alcohol and cigarette use were excluded from the study in both groups, and eventually, a number of women that did not match control group members were excluded. Data were analyzed with SPSS-18 using Fisher's exact test, Chisquare, student t-test, and Pearson Correlation Coefficient, and significant level was considered less than 0.05 .

\section{Results}

This study was conducted on case (235 women) and

Table 1. Comparison Case and Controls by Selected Descriptive Characteristics

\begin{tabular}{lccccc}
\hline Variable cancer & \multicolumn{2}{c}{ Case } & \multicolumn{2}{c}{ Control } & CI 95\% \\
\hline & $\begin{array}{c}\text { Number } \\
\text { 235 }\end{array}$ & \multicolumn{2}{c}{$\begin{array}{c}\text { Number } \\
235\end{array}$} & & \\
Age & & & & & \\
$\quad$ 40 years & 56 & 23.9 & 48 & 20.4 & $\mathrm{p}=0.163$ \\
40-49 years & 81 & 34.5 & 110 & 46.8 & \\
50-59 years & 71 & 30.1 & 64 & 27.2 & \\
360 years & 27 & 11.5 & 13 & 5.6 & \\
Mean & 47.6 & & 46.5 & \\
Age at Marriage & & & & & \\
\&14years & 28 & 11.9 & 40 & 17 & $\mathrm{p}=0.001$ \\
15-17 years & 61 & 26 & 76 & 32.3 & \\
18-20 years & 62 & 26.3 & 70 & 29.8 & \\
$>$ 20 years & 84 & 35.8 & 49 & 20.9 & \\
Occupation & & & & & \\
Worker & 18 & 7.6 & 21 & 8.9 & $\mathrm{p}=0.44$ \\
HOUSE Work & 217 & 92.4 & 214 & 91.1 & \\
Educational Level & & & & & \\
Illiterate & 126 & 53.6 & 118 & 50.2 & $\mathrm{p}=0.12$ \\
Primary & 95 & 40.2 & 99 & 42.1 & \\
Junior High & 5 & 2.1 & 8 & 3 & \\
Senior High & 7 & 2.9 & 6 & 2.4 & \\
College & 2 & 0.8 & 4 & 1.7 & \\
\hline
\end{tabular}

Table 2. Risk of Breast Cancer According to the Female Reproductive Factors

\begin{tabular}{|c|c|c|c|c|}
\hline \multirow[t]{2}{*}{ Variable cancer } & \multicolumn{3}{|c|}{ Breast Cancer } & \multirow[t]{2}{*}{$\mathrm{p}$} \\
\hline & Case 235 & Control 23 & & \\
\hline \multicolumn{5}{|l|}{ Age at menarche } \\
\hline$\leq 12$ & $8 \quad(3.4)$ & $28(12)$ & $0.2(0.11-0.52)$ & 0.171 \\
\hline 13 & $97(41.3)$ & $95(40.4)$ & $1.3(0.71-1.49)$ & \\
\hline 14 & $78(33.2)$ & $74(31.5)$ & $1.1(0.74-1.62)$ & \\
\hline$\geq 15$ years & $41(17.1)$ & $37(15.7)$ & $1.09(0.67-1.78)$ & \\
\hline Don't know & $11 \quad(4.7)$ & $1 \quad(0.4)$ & ----- & \\
\hline Mean & 14.9 & 13.78 & & \\
\hline \multicolumn{5}{|c|}{ Age at menopause } \\
\hline$<50$ years & $91(38.7)$ & $66(28.1)$ & $0.6(0.31-1.19)$ & 0.02 \\
\hline $50-59$ years & $32(13.6)$ & $15(6.4)$ & $1.5(0.75-2.99)$ & \\
\hline$\geq 60$ years & $4 \quad(2.7)$ & $1(0.4)$ & $2.63(0.28-23.9)$ & \\
\hline Premenopausal & $108(46.0)$ & $153(65.1)$ & $0.6(0.42-0.85)$ & \\
\hline Mean & 46.7 & 45.03 & & \\
\hline \multicolumn{5}{|c|}{ Age at first pregnancy } \\
\hline$\leq 14$ & $6(2.6)$ & $14(6.0)$ & $0.4(0.15-1.09)$ & 0.003 \\
\hline $15-17$ & $48(20.2)$ & $61(26.0)$ & $0.73(0.47-1.12)$ & \\
\hline $18-20$ & $71(29.8)$ & $77(33.1)$ & $0.8(0.6-1.31)$ & \\
\hline$>20$ & $110(46.4)$ & $83(34.9)$ & $1.63(1.13-2.37)$ & \\
\hline Mean & 21.48 & 19.66 & & \\
\hline \multicolumn{5}{|c|}{ Full term pregnancy } \\
\hline 1 & $19(8.1)$ & $6 \quad(2.6)$ & $2.78(1.20-6.42)$ & 0.022 \\
\hline 2 & $59(25.1)$ & $48(20.4)$ & $1.34(0.86-2.07)$ & \\
\hline 3 & $58(25.3)$ & $64(27.2)$ & $0.87(0.57-1.32)$ & \\
\hline$\geq 4$ & $99(41.5)$ & $117(49.8)$ & $0.72(0.50-1.03)$ & \\
\hline
\end{tabular}


Table 3. Risk of Breast Cancer According to the Use of Combination Oral Contraceptives

\begin{tabular}{|c|c|c|c|c|c|c|c|c|}
\hline \multirow[t]{2}{*}{ Group Pill users } & & \multicolumn{2}{|c|}{ Case } & \multicolumn{2}{|c|}{ Control } & \multicolumn{2}{|r|}{ OR } & \multirow{2}{*}{ CI $95 \%$} \\
\hline & & Number & Percent & Number & Percent & & & \\
\hline $\mathrm{OCP}$ & & 165 & 70.2 & 124 & 52.8 & 2.11 & $1.44-3.08$ & $\mathrm{p}=0.001$ \\
\hline Others & & 63 & 26.8 & 92 & 39.1 & & & \\
\hline \multirow[t]{5}{*}{ None } & & 7 & 3 & 19 & 8.1 & & & \\
\hline & $<12$ & 29 & 6.17 & 12 & 6.9 & 60.2 & $1.31-3.01$ & $\mathrm{p}=0.219$ \\
\hline & $13-60$ & 52 & 5.31 & 44 & 5.35 & 23.1 & $0.78-93.1$ & \\
\hline & $61-96$ & 17 & 3.1 & 11 & 9.8 & 58.1 & $0.72-3.46$ & \\
\hline & $\geq 97$ & 67 & 6.4 & 57 & 0.46 & 33.1 & $0.88-2.02$ & \\
\hline \multicolumn{9}{|c|}{ Age at onset of using OCP } \\
\hline & $13-18$ & 20 & 12.5 & 22 & 17.7 & 0.88 & $0.44-1.61$ & $\mathrm{p}=0.0001$ \\
\hline & $19-24$ & 64 & 38.5 & 69 & 55.7 & 0.9 & $0.61-1.34$ & \\
\hline & $25-30$ & 50 & 31.2 & 28 & 22.6 & 1.99 & $1.20-3.30$ & \\
\hline & $>30$ & 29 & 17.8 & 5 & 4 & 6.47 & $2.46-17.04$ & \\
\hline \multicolumn{9}{|c|}{ Age at discontinuing $\mathrm{OCP}$} \\
\hline & $<25$ & 20 & 12.1 & 25 & 20.2 & 0.78 & $0.42-1.44$ & $\mathrm{p}=0.004$ \\
\hline & $25-34$ & 47 & 28.4 & 43 & 34.6 & 1.11 & $0.75-1.76$ & \\
\hline & $35-44$ & 51 & 31 & 32 & 25.8 & 1.75 & $1.08-2.85$ & \\
\hline & $>45$ & 24 & 14.5 & 8 & 6.5 & 3.22 & $1.41-7.34$ & \\
\hline & Don’t know & 23 & 14 & 16 & 12.9 & & - & \\
\hline \multicolumn{9}{|c|}{ Time since last use } \\
\hline & $12>$ & 25 & 15.15 & 11 & 8.87 & 2.42 & $1.63-5.04$ & $\mathrm{p}=0.315$ \\
\hline & $12-36$ & 17 & 10.31 & 7 & 5.65 & 2.54 & $1.03-6.24$ & \\
\hline & $37-96$ & 37 & 22.42 & 25 & 20.16 & 1.65 & $0.91-2.70$ & \\
\hline & $>97$ & 86 & 52.12 & 81 & 65.32 & 1.09 & $0.75-1.60$ & \\
\hline & LD & 116 & 70.3 & 106 & 85.4 & 1.18 & $0.82-1.70$ & $\mathrm{p}=0.002$ \\
\hline & HD & 49 & 29.7 & 20 & 14.6 & 2.83 & $1.62-4.93$ & \\
\hline Used & & 165 & 2.7 & 124 & 8.52 & 11.2 & $1.44-3.08$ & $\mathrm{p}=0.001$ \\
\hline Didn't use & & 70 & 8.29 & 111 & 2.47 & & & \\
\hline
\end{tabular}

control (235 women) groups to investigate risk factors among women in West Azarbaijan Province. Results obtained showed that the majority of study subjects were aged 40 to 49 years, with the mean age in the case group 47.63 years and in control group 46.45 years. The two groups matched for age. Comparison of the two groups showed that the majority of study subjects were unemployed, illiterate, or with little literacy, with insignificant difference in terms of education level and employment status (socio-economic status). However, they were significantly different in terms of age at marriage $(\mathrm{p}=0.001)$ (Table 1). Results also showed that age at menarche was 13-14 years in the majority of subjects in the case group (176 women, $74.9 \%$ ) and in the control (169 women), $71.9 \%$ ), and in this respect, the difference between the groups was insignificant $(p=0.171)$. The majority of subjects in the case group (108 patients, $46 \%$ ) and in the control group (153 women, 65\%) were premenopausal. Results showed that the two groups were different in terms of menopause age and odds of breast cancer increased with increasing menopause age. The majority of subjects (111 women $(46.4 \%)$ in the case group, and $83(34.9 \%)$ in the control) had their first pregnancy after the age of 20 years, and there was a significant difference between the two groups in terms of age at the first pregnancy $(\mathrm{p}=0.003)$. History of the first pregnancy after age of 20 years increased risk of breast cancer $(\mathrm{OR}=1.63, \mathrm{CI} 95 \%)(1.13-2.37)$. In terms of number of pregnancies: risk of cancer is reduced with increasing number of pregnancies, so that those with cancer had fewer pregnancies, with a significant difference between the two groups $(\mathrm{p}=0.02)$. Odds ratio was 2.87 after the first pregnancy, 1.34 after the second, 0.87 after the third, and 0.72 after the fourth (Table 2). In terms of contraceptive use, $70.2 \%$ in the case group and $52.8 \%$ in the control used contraceptive pills. Chi-square test revealed a significant difference between the two groups $(p=0.001)$. In terms of duration of use, results showed mean duration of use was 94.5 month. in the case group, and 100.2 in the control, with an insignificant difference between two groups (Table 3). In terms of age at onset of use, there was a significant difference between use before and after 25 years of age, and in the case group, those that started taking pills at older age than 25 years, had higher odds ratio, compared to those that had their first use after age of 25 years. In relation to type of pill used, the difference between the two groups was significant, and among those with breast cancer, HD or a combination variety was used more (Table 3 ). In this study, there was an insignificant relationship between cervical cancer and factors such as age, discontinuation of pill use, and pattern of pill use (regular or alternate use).

\section{Discussion}

In this study, mean age of those with breast cancer was 47.63 years. In a study by Shamsaldin, mean age was 49.1 years [19]. Mean age was 49.18 years in Najefzar study (Zare et al., 2013) and 51.3 years in Mosavi study (Mosavi et al., 2006) In this study, it was found that age at affliction in West Azarbaijan Province was lower than in other parts of Iran (Gao et al., 2000; Tamakoshi et al., 2005) consider early menarche and late menopause a risk factor, and also Bernstein et al, have concluded that risk 
of breast cancer increases by $5 \%$ for every early menarche year and by $2.7 \%$ for every late menopause year (Bernstein et al., 2002; Tam et al., 2010). Results of an extensive study on 118964 women with breast cancer showed that early menarche and late menopause increased the risk [26]. In the present study, no relationship was found between age at menarche and incidence of breast cancer. Reliance on subjects' memory and passage of long time since menarche could have affected the above results. Also, there was a significant relationship between breast cancer and age at menopause, and with increasing menopause age to over 50 years, odds of cancer incidence reached 50.1, and more doubled in age over 60 years. A Chinese study showed that menopause after 50 years of age increased odds of breast cancer to 2.17, and menarche before 13 years of age increased the odds to 1.47 (Tam et al., 2010). Results of an extensive Japanese study on 38000 women showed no relationship between breast cancer and age at menarche or menopause (Tamakoshi et al., 2005). In Iran, menopause age may be lower than in some parts of the world. Also, mean age at diagnosis in this study was lower than in others, which could affect the results. Mean age at the first pregnancy in studies by Indian researchers was 21.6 years ( Pakseresht et al., 2009) and in the present study, mean age at the first pregnancy was 21.48 in the case group and 19.66 in the control group. In terms of age at first pregnancy, there was a significant difference between case and control group subjects, and those over 20 years of age had higher odds than control group, $\mathrm{OR}=1.63$ with $95 \%$ confidence interval (1.13-2.37). Some studies consider increased number of pregnancies as a protective factor against breast cancer. A Danish study indicated that more pregnancies reduce the risk of affliction (Ewertz et al., 1988). The present study showed $\mathrm{OR}=2.78$ for the first pregnancy, which reduced to $\mathrm{OR}=0.72$ after 4 pregnancies. Kelsey considers nulliparity after 40 years old dangerous (Kelsey et al., 1993). While, in the above study, it increased the odds in lower ages as well.

In relation to contraceptive types, contraceptive pills had the highest frequency in both case and control groups (70.2\% in case group, and $52.8 \%$ in control). In studies by Vessy et al. (1996) and Brinton et al. and Negrini et al. (1990), pills had the highest use compared to other contraceptive methods. In terms of history of use, the comparison showed a significant difference between the two groups. Wang et al. (1992) Stanford et al. (1995), Fasal et al. (1975) and Kumle et al. (2002) also found a relationship between history of use of pills and breast cancer. While in a study by Tavani on 373 patients and control group, under 40 years, no relationship was found between use of the pill and incidence of cancer (Tavani et al., 1993). Whiteman et al. (2007) not only did not find use of the pill a risk factor, but also considered it a protective factor. In this study, age groups had not been separated. Generally, in this study use of contraceptive pills doubled odds of breast cancer $\{\mathrm{OR}=2.11$, with $95 \%$ confidence interval (1.44-3.08)\}. Odds ratio was 2.2 in a study conducted in Isfahan Province (Ehsanpour et al., 2013) 2.38 in a study by Shobiri et al. (2010), and 3.02 in Paul's study. (Lodha et al., 2011).

In conclusion, results of this study showed that, in
Iran, age at being diagnosed with breast cancer is lower than in many parts of the world, and that incidence of breast cancer is associated with high age at the first pregnancy, high menopause age, nulliparity, and use of contraceptive pills, which double the incidence of breast cancer. Therefore, in Iran, screening for breast cancer in high-risk people is highly necessary.

Results of this study indicate that high risk women need more preventive actions and screening.

\section{References}

Ahmadian M, Asnarulkhadi A (2012). A model for community participation in breast cancer prevention in Iran. Asian Pac J Cancer Prev, 13, 2419-23.

Asnarulkhadi Abu S, Ahmadian M (2012). Socio-demographic correlates of participation in mammography: a survey among women aged between 35-69 in Tehran, Iran. Asian Pac J Cancer Prev, 13, 2717-20.

Brinton LA, Reeves WC, Brenes MM, et al (1990). Oral contraceptive use and risk of invasive cervical cancer. Int $J$ Epidemiol, 19, 4-11.

Iskandarsyah A, de Klerk C, Suardi DR, Sadarjoen SS, Passchier $J$ (2014). Health locus of control in indonesian women with breast. cancer: a comparison with healthy women. Asian Pac J Cancer Prev, 15, 9191-7.

Beiki O, Hall P, Ekbom A, Moradi T (2012). Breast cancer incidence and case fatality among 4.7 million women in relation to social and ethnic background: a population-based cohort study. Breast Cancer Res, 14, 5.

Bernstein L (2002). Epidemiology of endocrine-related risk factors for breast cancer. J Mammary Gland Biol Neoplasia, 7, 3-15.

Collaborative Group on Hormonal Factors in Breast Cance (2012). Menarche, menopause, and breast cancer risk: individual participant meta-analysis, including 118964 women with breast cancer from 117 epidemiological studies Original Text, The Lancet Oncology, Early Online Publication.

Collaborative Group on Hormonal Factors in Breast Cancer (1996). Breast cancer and hormonal contraceptives: collaborative reanalysis of individual data on 53297 women with breast cancer and 100239 women without breast cancer from 54 epidemiological studies. Lancet, 22, 1713-27.

Collaborative Group on Hormonal Factors in Breast Cancer (2001). Familial breast cancer: collaborative reanalysis of individual data from 52 epidemiological studies including 58,209 women with breast cancer and 101,986 women without the disease. Lancet, 358, 1389-99.

Collaborative Group on Hormonal Factors in Breast Cancer (2009). Risk factors with breast cancer among women in Delhi. Indian J Cancer, 46, 132-8.

Ehsanpour S, Ahmadi Nejad F, Mokarian Rajabi F, Taleghani F (2013). Investigation on the association between breast cancer and consumption patterns of combined oral contraceptive pills in the women of Isfahan in 2011. Iran J Nurs Midwifery Res, 18, 186-90.

Ewertz M, Duffy SW(1988). Risk of breast cancer in relation to reproductive factors in Denmark. Br J Cancer, 58, 99-104.

Fasal E, Paffenbarger RS Jr (1975). Oral contraceptives as related to cancer and benign lesions of the breast. J Natl Cancer Inst, 55, 767-73.

Gao YT, Shu XO, Dai Q, et al (2000). Association of menstrual and reproductive factors with breast cancer risk: results from the Shanghai breast cancer study. Int J Cancer, 87, 295-300.

Ghiasvand R, Setoudeh Maram E, Tahmasebi S, Tabatabaee SH 
(2011). Risk factors for breast cancer among young women in southern Iran. Intern J Cancer, 129, 1443-9.

Hadjiiski L, Sahiner B, Helvie M, et al (2006). Breast masses: computer: aided diagnosis with serial mammograms. Radiology, 240, 343-56.

Health Ministry of Iran (2010). Family planning office reported.

Kelsey JL, Gammon MD, John EM (1993). Reproductive factors and breast cancer. Epidemiol Rev,15(1),36-47.

Kumle M, Weiderpass E, Braaten T, et al (2002). Use of oral contraceptives and breast cancer risk: the norwegianSwedish women's lifestyle and health cohort study. Cancer Epidemiol Biomarkers Prev, 11, 1375-81.

Lodha R, Joshi A, Paul D, et al (2011). Association between reproductive factors and breast cancer in an urban set up at central India: a case-control study. Indian J Cancer, $\mathbf{4 8 ,}$ 303-7.

Vessy M, Painter (1996). Oral Contraceptive use and cancer. British J Cancer, 95, 385-9.

Michae IJ, Jemal A (2003). Cancer epidemiology, prevention and screening. cancer medicine. Hollan. Frei. Am Cancer Soc. Philadelphia: BC Decker Inc; p. 367-81.

Mousavi SM, Mohaghegghi MA, Mousavi-Jerrahi A, Nahvijou A, Seddighi Z (2006). Burden of breast cancer in Iran: a study of the Tehran population based cancer registry. Asian Pac J Cancer Prev, 7, 571-4.

Nagata C, Hu YH, Shimizu H (1995). Effects of menstrual and reproductive factors on the risk of breast cancer: metaanalysis of the case-control studies in Japan. Jpn J Cancer Res, 86, 910-5.

Negrini BP, Schiffman MH, Kurman RJ, et al (1990). Oral contraceptive use, human papillomavirus infection, and risk of early cytological abnormalities of the cervix. Cancer Res, 50, 4670-5.

Shamseddine AI, El Saghir NS, Geara F, et al (2002). Age distribution of breast cancer in Lebanon: increased percentages and age adjusted incidence rates of youngeraged groups at presentation. J Med Liban, 50, 3-9.

Stanford JL,Brinton LA, Daling JR, et al (1995). Oral contraceptives and breast cancer risk among younger women. J Natl Cancer Inst, 87, 827-35.

Tam CY, Martin LJ, Hislop G, et al (2010). Risk factors for breast cancer in postmenopausal Caucasian and Chinese-Canadian women. Breast Cancer Res, 12, 2.

Tamakoshi K, Yatsuya H, Wakai K, et al (2005). Impact of menstrual and reproductive factors on breast cancer risk in Japan: results of the JACC study. Cancer Sci, 96, 57-62.

Tavani A, Negri E, Franceschi S, Parazzini F, La Vecchia C (1993). Oral contraceptives and breast cancer in northern Italy. Final report from a case-control study. Br J Cancer, 68, 568-71.

Sabokbar T, Khajeh E, Taghdiri F, Peyghambari V, Shirkoohi R (2012). Familial breast cancer registry program in patients referred to the cancer institute of Iran. Asian Pac J Cancer Prev, 13, 2675-9.

Shobeiri F, Tehranian N, Pour FH, Hagizadeh E (2010). Risk factors for breast cancer in Iranian women aged less than 40 years. Asian Pac J Cancer Prev, 11, 1723-5.

Seth T, Kotwal A, Thakur RK, Ganguly KK (2012). A study on community perceptions of common cancers, determinants of community behaviour and programimplementation in New Delhi, India. Asian Pac J Cancer Prev, 13, 2781-9.

Wang QS, Ross RK, Yu MC, et al (1992). A case-control study of breast cancer in Tianjin, China. Cancer Epidemiol Biomarkers Prev, 1, 435-9.

Whiteman MK, Wingo PA, Austin H, et al (2007). Oral contraceptives and the risk of death from breast cancer. Obstet Gynecol, 110, 793-800.
Yip CH, Taib NA, Mohamed I (2006). Epidemiology of breast cancer in Malaysia. Asian Pac J Cancer Prev, 7, 369-74.

Zare N, Haem E, Kamran B, Lankarani Heydari ST, Barooti J (2013). Breast cancer risk factors in a defined population: weighted logistic regression approach for rare events breast cancer. J Breast Cancer, 16, 214-9.

Zeleniuch JA, Roy ES (2005). Epidemiology of breast cancer. in: Roses FD, editors. Breast Cancer. $2^{\text {nd }}$ ed. Philadelphia: Elsevier; p. 3-14. 